\title{
Identifying older diabetic patients at risk of poor glycemic control Raffaele Antonelli Incalzi ${ }^{1}$, Andrea Corsonello*2, Claudio Pedone, Francesco Corica ${ }^{3}$, Luciana Carosella ${ }^{1}$, Bruno Mazzei ${ }^{2}$, Francesco Perticone ${ }^{4}$ and PierUgo Carbonin ${ }^{1}$ for Gruppo Italiano di Farmacovigilanza nell'Anziano
}

Address: ${ }^{1}$ Istituto di Medicina Interna e Geriatria, Università Cattolica del Sacro Cuore, Rome, Italy, ${ }^{2}$ Divisione di Medicina Geriatrica, Istituto Nazionale di Ricerca e Cura Per Anziani (INRCA), Cosenza, Italy, ${ }^{3}$ Dipartimento di Medicina Interna, Università degli Studi di Messina, Italy and ${ }^{4}$ Dipartimento di Medicina Sperimentale e Clinica, Università degli Studi "Magna Graecia", Catanzaro, Italy

E-mail: Raffaele Incalzi - raffaele_antonelli@rm.unicatt.it; Andrea Corsonello* - andrea_corsonello@dada.it; Claudio Pedone - claudio_pedone@rm.unicatt.it; Francesco Corica - coricaf@www.unime.it;

Luciana Carosella - luciana_carosella@rm.unicatt.it; Bruno Mazzei - mazzeib@katamail.com; Francesco Perticone - perticone@unicz.it; PierUgo Carbonin - pierugo_carbonin@rm.unicatt.it; Gruppo Italiano di Farmacovigilanza nell'Anziano - andrea_corsonello@dada.it

${ }^{*}$ Corresponding author

Published: 23 August 2002

Received: 16 March 2002

BMC Geriatrics 2002, 2:4

Accepted: 23 August 2002

This article is available from: http://www.biomedcentral.com/I47I-23/8/2/4

(C) 2002 Incalzi et al; licensee BioMed Central Ltd. This article is published in Open Access: verbatim copying and redistribution of this article are permitted in all media for any non-commercial purpose, provided this notice is preserved along with the article's original URL.

\begin{abstract}
Background: Optimal glycemic control prevents the onset of diabetes complications. Identifying diabetic patients at risk of poor glycemic control could help promoting dedicated interventions. The purpose of this study was to identify predictors of poor short-term and long-term glycemic control in older diabetic in-patients.
\end{abstract}

Methods: A total of I 354 older diabetic in-patients consecutively enrolled in a multicenter study formed the training population (retrospective arm); 264 patients consecutively admitted to a ward of general medicine formed the testing population (prospective arm). Glycated hemoglobin ( $\mathrm{HbAlc}$ ) was measured on admission and one year after the discharge in the testing population. Independent correlates of a discharge glycemia $\geq 140 \mathrm{mg} / \mathrm{dl}$ in the training population were assessed by logistic regression analysis and a clinical prediction rule was developed. The ability of the prediction rule and that of admission $\mathrm{HbAlc}$ to predict discharge glycemia $\geq 140 \mathrm{mg} / \mathrm{dl}$ and $\mathrm{HbAlc}>7 \%$ one year after discharge was assessed in the testing population.

Results: Selected admission variables (diastolic arterial pressure $<80 \mathrm{mmHg}$, glycemia $=143-218$ $\mathrm{mg} / \mathrm{dl}$, glycemia $>218 \mathrm{mg} / \mathrm{dl}$, history of insulinic or combined hypoglycemic therapy, Charlson's index $>2$ ) were combined to obtain a score predicting a discharge fasting glycemia $\geq 140 \mathrm{mg} / \mathrm{dl}$ in the training population. A modified score was obtained by adding $I$ if admission $\mathrm{HbAlc}$ exceeded $7.8 \%$. The modified score was the best predictor of both discharge glycemia $\geq 140 \mathrm{mg} / \mathrm{dl}$ (sensitivity $=79 \%$, specificity $=63 \%$ ) and I year $\mathrm{HbAIc}>7 \%$ (sensitivity $=72 \%$, specificity $=71 \%$ ) in the testing population.

Conclusion: A simple clinical prediction rule might help identify older diabetic in-patients at risk of both short and long term poor glycemic control. 


\section{Background}

Optimal glycemic control has been proved to prevent the onset and/or to slow the progression of several complications of diabetes and, thus, to improve quality of life [1$4]$. Guidelines have been proposed to optimize the management of outpatients with diabetes and to assess the quality of the achieved glycemic control [5-16]. Attention has not been paid to the quality of glycemic control in people admitted to acute care hospital. Indeed, glycemic levels during the hospital stay, i. e. during a few days, are expected to lack any effect on the risk of complications which is related to the quality of glycemic control through several years. However, diabetic in-patients might represent a convenient sample for verifying whether any relationship exists between admission clinical/laboratory characteristics and the quality of glycemic control achieved at discharge and one year later. Targeting patients at risk of poor long term glycemic control could help promoting strategies to improve the quality of diabetes care.

Older diabetics represent the ideal population to be targeted because logistic problems frequently limit their access to ambulatory health care facilities. Furthermore, standards of care have been reported to be quite poor for a considerable proportion of older Medicare diabetic patients [17].

The present study has two objectives: 1) to develop a clinical prediction rule targeting older patients at risk of being discharged in poor glycemic control; 2) to verify whether the same prognostic model can predict long term poor glycemic control, as expressed by HbA1c > 7\% one year later.

\section{Methods \\ Study design}

The first part of this study aimed at developing a predictive score targeting subjects at risk of poor glycemic control at discharge in a population of diabetic patients enrolled in the GIFA (Gruppo Italiano di Farmacovigilanza nell'Anziano) study (retrospective arm of the study). The predictive score was, then, prospectively validated in a population of 264 diabetic in-patients consecutively admitted to a ward of general medicine. Accordingly, we will define "training" and "testing" population the ones in which the score was developed and validated, respectively [18]. The ability of both predictive score and admission HbA1c values to predict abnormal HbA1c one year after discharge was assessed in the testing population. The study design was approved by Ethical Committees of participating institutions. Patients gave their informed consent to participate in the study. The study design is summarized in figure 1 (see additional file: figure1.ppt).

\section{Training population: data source}

We used data collected by the GIFA in six non consecutive periods (May - June and September - October in the years 1993, 1995 and 1997). The design of the GIFA study has been described elsewhere $[19,20]$. The study aimed at assessing drug use at home and in the hospital by a standardized protocol. All patients admitted to participating centers (32 wards of Geriatrics and 37 wards of Internal Medicine) during the study period were recruited without exclusion criteria. A study physician completed a questionnaire on admission recording demographic and personal information (such as smoking habit, household composition), functional and cognitive status. Results of laboratory tests performed at admission and at the time of discharge were also collected. Serum glucose was assessed by the hexokinase method. The study physician updated the questionnaire daily with detailed information on the therapy prescribed and finally recorded discharge diagnoses and prescriptions.

\section{Training population: selection criteria}

The number of patients enrolled in the GIFA study in the period we considered was 14,037 . We excluded persons younger than 65 years $(n=3,311)$ and those who died during the hospital stay $(n=751)$. Of the 9,982 remaining patients, 1,833 (18.4\%) had a diagnosis of diabetes mellitus, identified by the codes 250.0 - 250.6; 250.7; 250.9; 337.1 - 357.2; 354.5; 355.9; 358.1; 362.0; 366.4; 443.8, $581.8,582.8,583.8$ of the International Classification of Disease [21]. We then excluded those with missing data on glycemia or any other of the variables to be tested as potential correlates of the quality of achieved glycemic control $(n=479)$. These variables assess health status, type of hypoglycemic therapy prior to admission, comorbidity and severity of the metabolic derangement, as expressed by selected laboratory and clinical parameters. The 1,354 remaining patients formed the training population.

\section{Training population: clinical measures}

Height and weight were measured while the patient was fasting and wore light clothing. Weight of dehydrated or edematous patients was measured after the achievement of the euvolemic status. Then, Body Mass Index (BMI = weight $/$ height $^{2}$ ) was computed.

We measured the performance on the Activities of Daily Living (ADLs: dressing, bathing, transferring, toileting, walking, eating) [22], and divided patients in the following three categories: independent in all ADLs, dependent on external help in 1 to 5 ADLs, dependent on external help in all ADLs.

Cognitive status was assessed by the Abbreviated Mental Test (AMT), which is a 10-item screening test for dementia 


\section{Retrospective arm of the study}

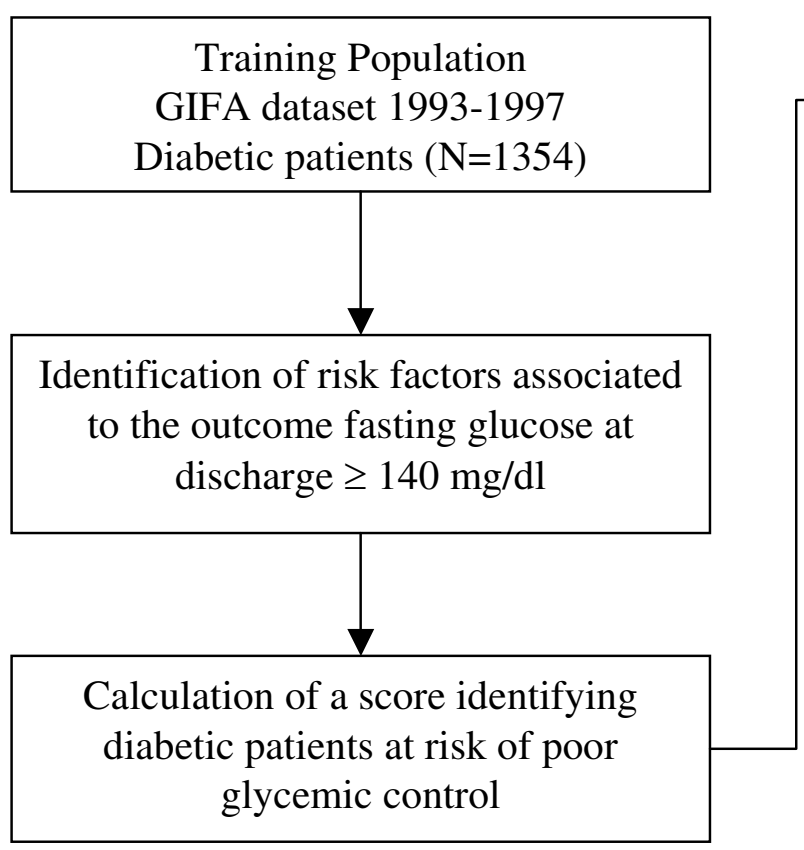

\section{Prospective arm of the study}

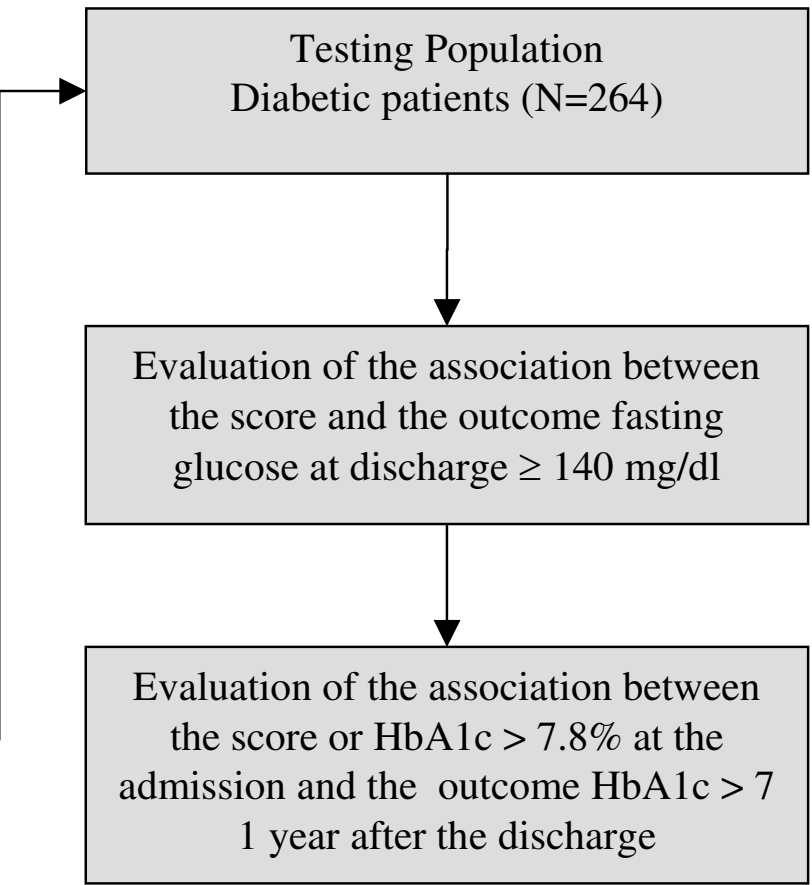

Figure I

Design of the study.

validated in Italy $[23,24]$. We considered abnormal a score lower than 7. This cut-off level for AMT score has been reported to yield 100\% sensitivity and 71\% specificity with respect to the DSM III diagnosis criteria of dementia [24].

Comorbidity was measured according to Charlson et al. [25].

The hospital staff measured arterial blood pressure at the time of the patient's admission. The average of two consecutive measurements was considered. Heart rate was measured on an electrocardiographic strip.

On admission, the study physician requested the patients and/or, if necessary, their relatives or caregivers to display all containers for drugs taken during the last two weeks prior to admission or to recall the names of drugs. Also, the study physician recorded daily all the drugs prescribed during the hospital stay (including dosage), as well as those prescribed at discharge. Drugs were codified according to Anatomical, Therapeutic and Chemical codes, version 9th [26]. In the present study, we considered only oral hypoglycemic agents and insulin for analysis.

\section{Testing population}

It included 264 diabetic patients selected out of the 399 admitted to a ward of general medicine of an acute care hospital (University Hospital of Messina) in 1999-2000 to be matched to the training population for age, gender and education as well as for performance on AMT and ADL (prospective arm of the study). Discharged patients were seen by internists in the outpatient department every 3 to 6 months depending upon the individual needs.

Clinical characteristics and values of selected laboratory indexes were systematically collected as in the training population. HbA1c levels were measured by HPLC (Dia- 
Table I: Comparison among training population and patients excluded from the analysis because of missing data

\begin{tabular}{|c|c|c|c|c|}
\hline & $\begin{array}{l}\text { Training population } \\
(\mathrm{N}=1354)\end{array}$ & $\begin{array}{l}\text { Patients excluded } \\
(\mathrm{N}=479)\end{array}$ & $\mathrm{t}$ & $P$ \\
\hline Age (yrs) & $77.0 \pm 6.7$ & $77.9 \pm 7.2$ & -2.524 & 0.012 \\
\hline Gender (males) & $577(42.6)$ & $209(43.6)$ & & 0.699 \\
\hline BMI $\left(\mathrm{kg} / \mathrm{m}^{2}\right)$ & $26.3 \pm 4.8$ & $25.6 \pm 4.6$ & 2.495 & 0.013 \\
\hline Systolic blood pressure $(\mathrm{mmHg})$ & $149 \pm 26$ & $149 \pm 25$ & -0.038 & 0.969 \\
\hline Diastolic blood pressure $(\mathrm{mmHg})$ & $82 \pm 14$ & $82 \pm 13$ & 0.591 & 0.555 \\
\hline Education (yrs) & $5.4 \pm 3.3$ & $5.0 \pm 2.9$ & 2.377 & 0.018 \\
\hline Type of ward & & & & 0.023 \\
\hline Geriatrics & $961(71.0)$ & $343(71.6)$ & & \\
\hline Medicine & $366(27.0)$ & $135(28.2)$ & & \\
\hline Others & $27(2.0)$ & $\mathrm{I}(0.2)$ & & \\
\hline Charlson & $2.5 \pm 1.8$ & $2.5 \pm 1.6$ & 0.878 & 0.380 \\
\hline AMT & $6.9 \pm 3.0$ & $6.9 \pm 3.1$ & 0.308 & 0.758 \\
\hline$A D L$ & & & & 0.821 \\
\hline Independent & $661(48.8)$ & $234(48.9)$ & & \\
\hline Assistance & $292(21.6)$ & $98(20.5)$ & & \\
\hline Dependent & $390(28.8)$ & $144(30.1)$ & & \\
\hline Hypoglycemic therapy prior to admission & & & & 0.002 \\
\hline Diet alone & $659(48.7)$ & $263(54.9)$ & & \\
\hline Oral agents alone & $444(32.8)$ & $160(33.4)$ & & \\
\hline Insulin alone & $213(15.7)$ & $42(8.8)$ & & \\
\hline Oral agents and insulin & $38(2.8)$ & $14(2.9)$ & & \\
\hline Plasma glucose (mg/dl) & $198 \pm 102$ & $159 \pm 78$ & 7.459 & 0.001 \\
\hline Cholesterol (mg/dl) & $189 \pm 53$ & $|84 \pm 5|$ & 1.658 & 0.098 \\
\hline Triglycerides (mg/dl) & $162 \pm 108$ & $149 \pm 98$ & 2.020 & 0.044 \\
\hline White blood cells (cells $/ \mathrm{mm}^{3}$ ) & $8576 \pm 4337$ & $8564 \pm 6100$ & 0.044 & 0.965 \\
\hline Serum sodium $(\mathrm{mEq} / \mathrm{l})$ & $139 \pm 4.5$ & $139 \pm 4.3$ & -0.354 & 0.723 \\
\hline Serum potassium (mEq/l) & $4.3 \pm 0.6$ & $4.3 \pm 0.6$ & 2.275 & 0.023 \\
\hline
\end{tabular}

Data are means $\pm S D$ or number of cases with percent in parentheses.

man DM BioRad, Segrate - Milano, Italy) both on admission and one year after the discharge. The latter measurement was made on 199 patients. Nineteen out of the remaining 65 patients were dead at the time of follow up, whereas 46 refused to participate or could not be tracked.

\section{Data analysis}

In order to define the profile of patients at risk of poor glycemic control, we considered socio-demographic data (age, sex, years of formal education), select laboratory findings (glycemia, cholesterol, triglycerides, sodium, potassium, creatinine, white cell count), BMI, Charlson's index, AMT and ADL scores. We categorized laboratory parameters using the tertiles of their distribution to make the comparisons more meaningful from a clinical point of view. We classified anti-diabetic therapy as follows: diet alone if no drugs were prescribed, oral hypoglycemic therapy alone, insulin alone, combined oral hypoglycemic therapy and insulin.
The glycemic control achieved at discharge was considered as inadequate if fasting glycemia exceeded $140 \mathrm{mg} / \mathrm{dl}$ [27]. This threshold was used because the study period antedated the revision of normal glycemic standards proposed in 1999 [28]. Admission variables univariately associated with the outcome glycemia $\geq 140 \mathrm{mg} / \mathrm{dl}$ at discharge were entered into a logistic regression analysis aimed at identifying independent correlates of the outcome [29]. Selected variables were excluded from the logistic regression to limit multicollinearity with admission glycemia. The analysis was repeated for patients admitted to the hospital after the introduction of the Diagnosis Related Payment (DRG) system as well as for those who were hospitalized primarily because of diabetes mellitus. This precautionary measure aimed at excluding that the DRG-related shortening of the stay and/or differences in the clinical importance of diabetes could affect the model predicting poor glycemic control at discharge.

We developed a score to target patients at risk of poor glycemic control. Variables recognized to be independently 
Table 2: Demographic, historical, clinical and laboratory correlates of fasting plasma glucose $\geq 140 \mathrm{mg} / \mathrm{dl}$ at discharge in the training population

\begin{tabular}{|c|c|c|c|c|}
\hline & \multicolumn{3}{|c|}{ Fasting plasma glucose at discharge } & \multirow[b]{2}{*}{$95 \% \mathrm{Cl}$} \\
\hline & $<140$ & $\geq 140$ & $\mathrm{OR}^{*}$ & \\
\hline Age (yrs) & $76.8 \pm 6.8$ & $77.2 \pm 6.7$ & 1.01 & $0.99-1.02$ \\
\hline Gender (males) & $332(44.9)$ & $245(39.8)$ & 0.82 & $0.66-1.02$ \\
\hline BMI $\left(\mathrm{kg} / \mathrm{m}^{2}\right)$ & $26.1 \pm 4.8$ & $26.7 \pm 4.8$ & 1.02 & $1.0-1.05$ \\
\hline \multicolumn{5}{|c|}{ Systolic blood pressure $(\mathrm{mmHg})$} \\
\hline$<140$ & $130(17.6)$ & $116(18.9)$ & 1.0 & \\
\hline $140-160$ & $370(50.1)$ & $299(48.6)$ & 0.89 & $0.66-1.19$ \\
\hline$>160$ & $239(32.3)$ & $200(32.5)$ & 0.92 & $0.67-1.26$ \\
\hline \multicolumn{5}{|c|}{ Diastolic blood pressure $(\mathrm{mmHg})$} \\
\hline$<80$ & 101 (13.7) & $126(20.5)$ & 1.0 & \\
\hline $80-90$ & $452(6 \mid .2)$ & $320(52.0)$ & 0.56 & $0.4 I-0.75$ \\
\hline$>90$ & $186(25.2)$ & $169(27.5)$ & 0.71 & $0.51-0.99$ \\
\hline \multicolumn{5}{|l|}{ Education (yrs) } \\
\hline$<5$ & $240(32.5)$ & $227(36.9)$ & 1.0 & \\
\hline $5-8$ & $349(47.2)$ & $261(42.4)$ & 0.82 & $0.64-1.05$ \\
\hline$>8$ & $91(12.3)$ & $57(9.3)$ & 0.70 & $0.47-1.04$ \\
\hline \multicolumn{5}{|l|}{ Type of ward } \\
\hline Geriatrics & $532(72.0)$ & $429(69.8)$ & 1.0 & \\
\hline Medicine & $195(26.4)$ & $17 \mid(27.8)$ & 1.09 & $0.86-1.39$ \\
\hline Others & $12(1.6)$ & $15(2.4)$ & 1.63 & $0.75-3.53$ \\
\hline \multicolumn{5}{|l|}{ Charlson } \\
\hline $0-1$ & $265(35.9)$ & $206(33.5)$ & 1.0 & \\
\hline 2 & $193(26.1)$ & $136(22.1)$ & 0.92 & $0.69-1.23$ \\
\hline $3+$ & $281(38.0)$ & $273(44.4)$ & 1.28 & $1.01-1.64$ \\
\hline \multicolumn{5}{|l|}{ AMT } \\
\hline$\geq 7$ & $483(65.4)$ & $386(62.8)$ & 1.0 & \\
\hline$<7$ & $244(33.0)$ & $216(35.1)$ & 1.06 & $0.83-1.34$ \\
\hline \multicolumn{5}{|l|}{$A D L$} \\
\hline Independent & $365(49.4)$ & $296(48.1)$ & 1.0 & \\
\hline Assistance & $175(23.7)$ & $117(19.0)$ & 0.80 & $0.60-1.06$ \\
\hline Dependent & $192(26.0)$ & $198(32.2)$ & 1.23 & $0.95-1.60$ \\
\hline \multicolumn{5}{|c|}{$\begin{array}{l}\text { Hypoglycemic therapy prior to admis- } \\
\text { sion }\end{array}$} \\
\hline Diet alone & $386(52.2)$ & $273(44.4)$ & 1.0 & \\
\hline Oral agents alone & $253(34.2)$ & $191(31.1)$ & 1.05 & $0.83-1.35$ \\
\hline Insulin alone & $86(11.6)$ & $127(20.7)$ & 2.07 & $1.5 \mathrm{I}-2.84$ \\
\hline Oral agents and insulin & 14 (1.9) & $24(3.9)$ & 2.40 & $1.22-4.74$ \\
\hline \multicolumn{5}{|l|}{ Plasma glucose (mg/dl) } \\
\hline$<143$ & $344(46.5)$ & $110(17.9)$ & 1.0 & \\
\hline$|43-2| 8$ & $233(31.5)$ & $218(35.4)$ & 2.90 & $2.18-3.85$ \\
\hline$>218$ & $162(21.9)$ & $287(46.7)$ & 5.50 & $4.12-7.34$ \\
\hline \multicolumn{5}{|l|}{ Cholesterol (mg/dl) } \\
\hline$<164$ & $237(32.1)$ & $183(29.8)$ & 1.0 & \\
\hline $164-208$ & $245(33.2)$ & $185(30.1)$ & 0.96 & $0.73-1.26$ \\
\hline$>208$ & $212(28.7)$ & $209(34.0)$ & 1.24 & $0.93-1.63$ \\
\hline \multicolumn{5}{|l|}{ Triglycerides (mg/dl) } \\
\hline$<110$ & $232(31.4)$ & $143(23.3)$ & 1.0 & \\
\hline $110-168$ & $217(29.4)$ & $175(28.5)$ & 1.31 & $0.98-1.75$ \\
\hline$>168$ & $185(25.0)$ & $193(31.4)$ & 1.67 & $1.24-2.23$ \\
\hline \multicolumn{5}{|l|}{ White blood cells (cells/mm³) } \\
\hline$<6800$ & $248(33.6)$ & $196(31.9)$ & 1.0 & \\
\hline $6800-8970$ & $262(35.5)$ & $186(30.2)$ & 0.90 & $0.69-1.17$ \\
\hline$>8970$ & $224(30.3)$ & $225(36.6)$ & 1.28 & $0.98-1.67$ \\
\hline
\end{tabular}


Table 2: Demographic, historical, clinical and laboratory correlates of fasting plasma glucose $\geq 140 \mathrm{mg} / \mathrm{dl}$ at discharge in the training population (Continued)

\begin{tabular}{|c|c|c|c|c|}
\hline \multicolumn{5}{|c|}{ Serum sodium $(\mathrm{mEq} / \mathrm{l})$} \\
\hline$<138$ & $185(25.0)$ & $210(34.1)$ & 1.0 & \\
\hline$|38-| 4 \mid$ & $300(40.6)$ & $230(37.4)$ & 0.68 & $0.52-0.88$ \\
\hline$>|4|$ & $242(32.7)$ & $169(27.5)$ & 0.61 & $0.46-0.80$ \\
\hline \multicolumn{5}{|c|}{ Serum potassium $(\mathrm{mEq} / \mathrm{l})$} \\
\hline$<4.1$ & $237(32.1)$ & $185(30.1)$ & 1.0 & \\
\hline $4.1-4.6$ & $294(39.8)$ & $260(42.3)$ & 1.13 & $0.88-1.46$ \\
\hline$>4.6$ & $200(27.1)$ & $165(26.8)$ & 1.05 & $0.79-1.39$ \\
\hline
\end{tabular}

Data are means $\pm S D$ or number of cases with percent in parentheses. Data may not yeld $100 \%$ because of missing data. ${ }^{*}$ Odds ratios adjusted for age and gender.

correlated with the outcome were assigned a score whose magnitude ranged between 0 and 5 and was directly proportional to the corresponding odds ratio. The final score for the individual patient was obtained by summing partial scores, i. e. those corresponding to predictors collected in that patient. The ability of the score to predict the outcome glycemia $\geq 140 \mathrm{mg} / \mathrm{dl}$ control at discharge and the best cut off value of the score were assessed by measuring the area under the receiving operating characteristic (ROC) curve in the testing population [30].

Statistical analysis was performed using SPSS software package version 10.0 (SPSS Inc, Chicago, IL, USA).

The predictive score was validated in the testing population. In this population, we calculated also the sensitivity and specificity of HbA1c in detecting the probability of poor glycemic control at discharge, using a cut off value of $7.8 \%$, which was empirically identified as the best cut off level. We obtained a modified score by adding 1 to the original score in patients with admission $\mathrm{HbA} 1 \mathrm{c}>7.8 \%$. Finally, we compared the diagnostic accuracy of the three predictors (the predictive score, HbA1c $>7.8 \%$ on admission, and the modified score) versus the outcome HbA1c $>7 \%$ one year after the discharge.

\section{Results}

The main characteristics of the training population and of patients excluded from the study because of incomplete data recording are reported in Table 1. Excluded patients were slightly older and had lower formal education and BMI, but comparable level of comorbidity, physical and cognitive performance. They were in better metabolic control, as reflected by lower admission serum glycemia and triglycerides and lesser use of insulin prior to admission (Table 1).

Patients enrolled in the training population were grouped according to whether their glycemia at discharge was or not inferior to $140 \mathrm{mg} / \mathrm{dl}$ (Table 2). Groups had compara- ble age, prevalence of males, educational level, nutritional status, cognitive and physical capabilities. Diabetes mellitus was the cause of hospitalization in $16.1 \%$ of patients discharged with glycemia $<140 \mathrm{mg} / \mathrm{dl}$ and $22.6 \%$ of patients discharged with glycemia $>139 \mathrm{mg} / \mathrm{dl}$. The allocation to a ward of Geriatrics or General Medicine was unrelated to the outcome glycemic control, whereas the use of insulin alone or with oral hypoglycemic agents prior to admission, diastolic hypotension on admission and a Charlson's index greater than 2 were more common among patients having fasting glycemia $\geq 140 \mathrm{mg} / \mathrm{dl}$ at discharge. The higher the glycemia on admission the greater the risk of not achieving a satisfactory glycemic control at discharge. Also hypertrygliceridemia and hyponatremia on admission were more prevalent among patients discharged with glycemia $\geq 140 \mathrm{mg} / \mathrm{dl}$.

Logistic regression analysis identified five admission variables independently correlated with poor glycemic control at discharge: diastolic arterial pressure lower than 80 $\mathrm{mmHg}$, glycemia $=143-218 \mathrm{mg} / \mathrm{dl}$, glycemia $>218 \mathrm{mg} /$ $\mathrm{dl}$, use of insulin with or without oral hypoglycemic agents in the two weeks prior to admission, Charlson's index $>2$ (Table 3 ). We did not include hypertrygliceridemia in the model because of the collinearity with admission hyperglycemia, which likely reflects the parallelism between serum levels of glucose and tryglicerides in decompensated diabetes. Logistic regression analyses limited to the DRG era (1995-1997) and to patients for whom diabetes was the cause of admission confirmed results achieved in the whole population.

In an attempt to interpret the relationship between lower diastolic pressure and poor metabolic control, we characterized hypotensive patients and found that a greater Charlson's index $(2.8 \pm 2.2$ vs. $2.5 \pm 1.7, \mathrm{p}<0.005)$ and lower cholesterol level ( $169 \pm 50$ vs. $193 \pm 53 \mathrm{mg} / \mathrm{dl}, \mathrm{p}<$ $.001)$ were the hallmark of this subset. 
Table 3: Results of logistic regression analysis having plasma glucose $\geq 140 \mathrm{mg} / \mathrm{dl}$ at discharge as the dependent variable in the training population

\begin{tabular}{|c|c|c|c|c|}
\hline \multicolumn{5}{|c|}{ Fasting plasma glucose at discharge } \\
\hline & $<140$ & $\geq 140$ & OR & $95 \% \mathrm{Cl}$ \\
\hline Age (years) & $76.8 \pm 6.8$ & $77.2 \pm 6.7$ & 1.01 & $0.99-1.03$ \\
\hline Gender (males) & $332(44.9)$ & $245(39.8)$ & 0.88 & $0.70-1.12$ \\
\hline Diastolic blood pressure $<80 \mathrm{~mm} \mathrm{Hg}^{*}$ & $101(13.7)$ & $126(20.5)$ & 1.63 & $1.19-2.22$ \\
\hline \multicolumn{5}{|l|}{ Plasma glucose on admission $(\mathrm{mg} / \mathrm{dl})$} \\
\hline$<143$ & $344(46.5)$ & $110(17.9)$ & 1.0 & 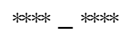 \\
\hline$|43-2| 8^{*}$ & $233(31.5)$ & $218(35.4)$ & 2.84 & $2.13-3.79$ \\
\hline$>218^{*}$ & $162(21.9)$ & $287(46.7)$ & 5.29 & $3.91-7.15$ \\
\hline White blood cells $>8970$ cells $/ \mathrm{mm}^{3}$ & $224(30.3)$ & $225(36.6)$ & 1.09 & $0.85-1.40$ \\
\hline Serum sodium < I 38 mEq/l & $185(25.0)$ & $210(34.1)$ & 1.02 & $0.78-1.33$ \\
\hline $\begin{array}{l}\text { Insulin or combined hypoglycemic ther- } \\
\text { apy prior to admission* }\end{array}$ & $100(13.5)$ & $151(24.6)$ & 2.03 & $1.50-2.75$ \\
\hline Charlson's Index $>2^{*}$ & $28 I(38.0)$ & $273(44.4)$ & 1.32 & $1.04-1.67$ \\
\hline
\end{tabular}

Data are means $\pm S D$ or number of cases with percent in parentheses. * Marks variables found to be independently correlated with the outcome.

A score predicting poor glycemic control was developed as follows: each independent correlate of the outcome was assigned a score whose magnitude was directly proportional to the corresponding odds ratio. The score for admission glycemia $>218 \mathrm{mg} / \mathrm{dl}$ was arbitrarily established to be 5 , while scores of the remaining predictors were computed according to the ratio between odds ratios of glycemia $>218 \mathrm{mg} / \mathrm{dl}$ and that of individual predictors obtained by the logistic regression analysis and were approximated to the unit. For example, the score of glycemia $=143-218$ was computed by solving the following proportion: $2.84: 5.29=\mathrm{x}: 5$ and was found to be 2.7 , which was approximated to 3 . Insulin therapy prior to admission and diastolic arterial pressure inferior to $80 \mathrm{mmHg}$ scored 2, Charlson's index $>2$ scored 1. For each patient a final score was obtained by summing scores of individual predictors. Thus, a subject who used insulin prior to admission, had admission glycemia $=268 \mathrm{mg} / \mathrm{dl}$ and Charlson's index $=3$ scored 8 , i. e. $2+5+1=8$.

Selected indexes of diabetes severity and the distribution of the predictive score in the testing population are summarized in Table 4. The distribution of the score levels was used to compute the corresponding pairs of sensitivity and specificity values used for drawing the ROC curve (Figure 2) (see additional file: figure2.bmp). The area under the curve was 0.72 , which is consistent with a good, but not excellent predictive model. The cut off level of the predictive score achieving the best discrimination of patients was 4 and had sensitivity of $76 \%$ and specificity of $60 \%$. These figures were comparable with sensitivity $(79 \%)$ and specificity $(63 \%)$ achieved by the level 5 of the

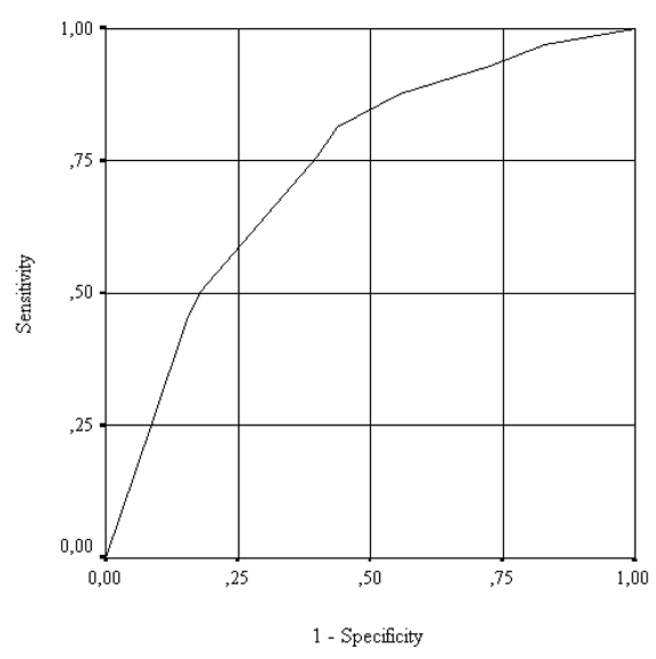

Figure 2

Receiving operating characteristic (ROC) curve of the predictive score versus the outcome poor glycemic control at discharge in the testing population.

In the testing population, HbA1c levels on admission and the predictive score were highly correlated ( rho $=0.58, \mathrm{p}$ $<0.001$ ). Quartiles of HbA1c could predict the outcome glycemic control at discharge at least as effectively as the original and the modified predictive scores: HbA1c $>7.8$ $\%$, corresponding to the lower limit of the third quartile, had sensitivity of $85 \%$ and specificity of $60 \%$ versus the outcome poor glycemic control at discharge. 
Table 4: Selected indexes of diabetes severity and distribution of the predictive score in the testing population *

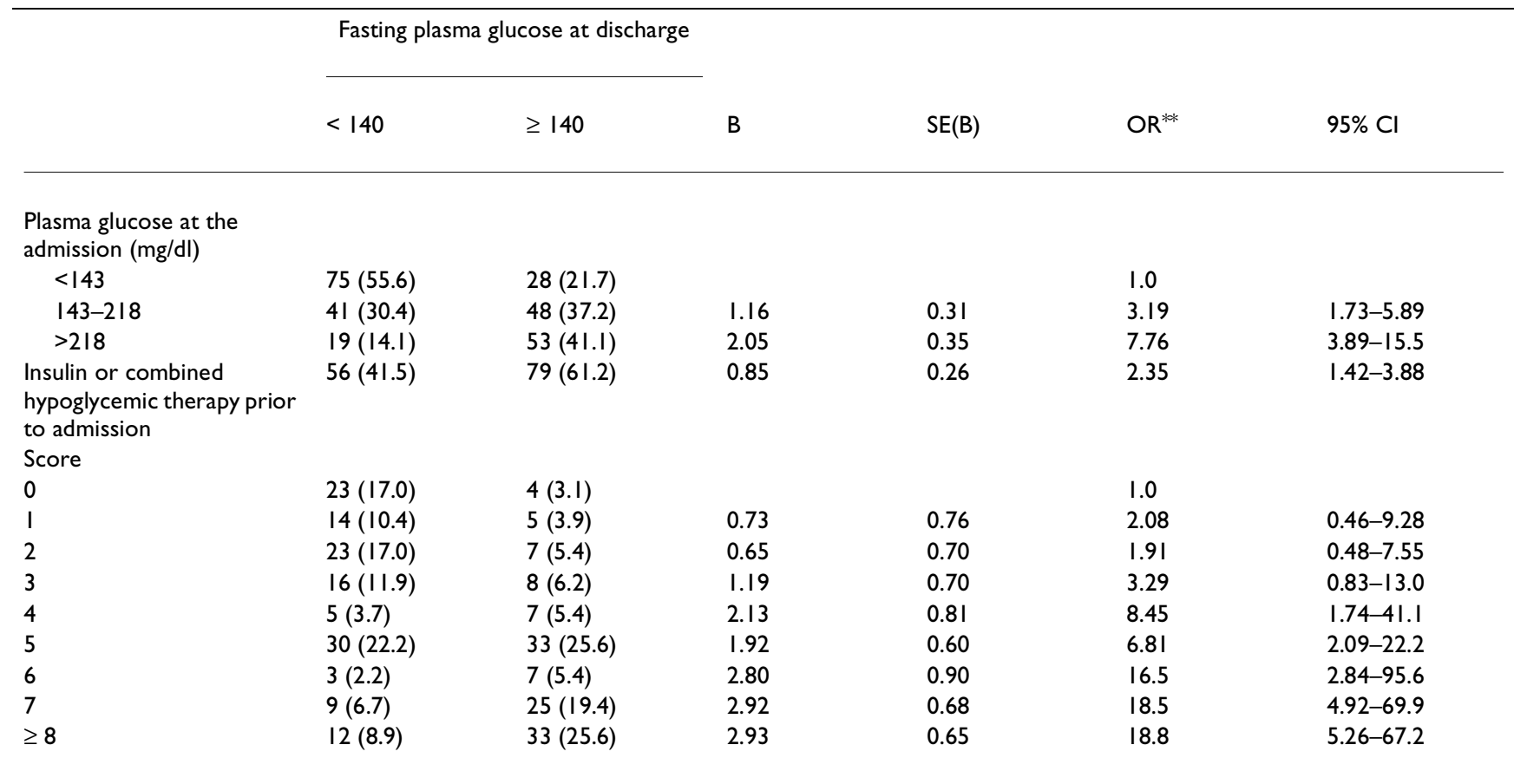

\footnotetext{
* See the text, section "Results", for the method of computing the predictive score. ${ }^{* *}$ Adjusted for age and gender. Data in columns 2 and 3 are numbers (percentage).
}

Table 5: Sensitivity and specificity of the predictive score, $\mathrm{HbAlc}>7.8 \%$ at the admission and the modified score versus the outcome $\mathrm{HbAlc}>7 \%$ one year after the discharge in the testing population

\begin{tabular}{llll}
\hline & Score (level 4) & HbAlc >7.8\% at admission & Modified score (level 5) \\
\hline Sensitivity, \% & 66 & 69 & 72 \\
Specificity, \% & 71 & 56 & 71 \\
Positive predictive value, \% & 81 & 75 & 79 \\
Negative predictive value, \% & 57 & 56 & 58 \\
\hline
\end{tabular}

Sensitivity: True positives/(True positives + False negatives); Specificity: True negatives/(True negatives + false positives); Positive predictive value: True positives/(True positives + False positives); Negative predictive value: True negatives/(True negatives + False negatives).

When compared with the predictive score and HbA1c $>7.8 \%$ on admission, the modified predictive score showed the best mix of sensitivity (72\%) and specificity (71\%) towards the outcome HbA1c > 7\% one year after discharge (Table 5). It could target accurately diabetics at risk of long term poor metabolic control (positive predictive value: $79 \%$ ), but not those likely to have their diabetes well compensated one year after the discharge (negative predictive value: $58 \%$ ).

\section{Discussion}

This study demonstrates that over $50 \%$ of older diabetic patients are discharged from wards of general medicine and geriatrics of the acute care hospital in poor metabolic control and can be reliably identified by an admission value of $\mathrm{HbA1c}>7.8 \%$ or a simple clinical prediction rule. More importantly, these predictive tools effectively target patients exposed to a significant risk of poor long term glycemic control. The clinical prediction rule has greater specificity than $\mathrm{HbA} 1 \mathrm{c}>7.8 \%$ in predicting poor long term glycemic control, i.e. it outweighs HbA1c $>7.8 \%$ in 
targeting subjects who will have their diabetes well controlled one year after being discharged.

Patients with more advanced diabetes, as reflected by the systematic use of insulin at home and/or glycemia $>218$ $\mathrm{mg} / \mathrm{dl}$ on admission, were at special risk of being discharged in poor glycemic control. Hypotension on admission was another risk factor for poor glycemic control likely because of its association with polipathology. Indeed, physicians are expected to encounter greater difficulty in tailoring the hypoglycemic therapy to the needs of patients in more unstable conditions and to compensate them more cautiously.

The analysis limited to the 1995-1997 period excluded that the mechanism of the payment based upon the Diagnosis-Related Group could have unduly shortened the stay and, thus, prevented the achievement of optimal glycemic control. On the contrary, in the United States the introduction of the Diagnosis-Related Group payment system could have worsened the quality of care provided to diabetic patients [31]. These observations caution against generalizing the present results to other health systems.

Achieving a satisfactory metabolic control is the only measure proven to prevent diabetic microvascular and neuropathic complications [1-4]. Unfortunately, such an objective was missed in a consistent proportion of diabetic patients, as $65.8 \%$ of them had high HbA1c levels one year after discharge. The necessity of balancing the benefit of glycemic control towards the risk of hypoglycemia only to some extent justifies such a result. Indeed, the protective effect of optimal glycemic control towards selected diabetic complications and the ensuing improvement in quality of life largely outweigh the risk of hypoglycemic episodes [1-4]. Furthermore, sustained improvement in glycemic control results in significant health cost saving with a lag time of 1 or 2 years [32]. However, our population was older than that enrolled in the UKPDS trials and by Wagner et al. Older age is associated with reduced sensitivity to neurovegetative effects of hypoglycemia [33]. Furthermore, social factors such as lack of both formal and informal support caution against an overzealous treatment of diabetes, mainly in patients with cognitive impairment or defective vision. However, lack of data on older diabetic populations prevented us from choosing levels of optimal metabolic control different from those reported to protect from microvascular complications. In this perspective, HbA1c > 7\% likely represents a convenient index of poor long term metabolic control, whereas glucose $\geq 140 \mathrm{mg} / \mathrm{dl}$ seems a questionable short term index of metabolic decompensation. Indeed, achieving the optimal glycemic control might not be the primary out- come of in-patient management if comorbidity and frailty coexist with diabetes.

The recent experience shows that a considerable lag time exists between the unequivocal demonstration and the increase in the use of important and even lifesaving drugs such as ace-inhibitors for congestive heart failure; nevertheless, rate of use still remains far from the optimal one $[34,35]$. It is likely that the optimization of hypoglycemic therapy will follow a similar time course. Indeed, the benefit of optimal glycemic control has been definitively proven in 1998 and further confirmed in 1999-2000. However, a pessimistic attitude towards diabetes rather than an insufficient knowledge of this disease seems to hinder the implementation of management guidelines by physicians, at least by primary care providers [36]. Furthermore the poor quality of documentation sent to the general practitioners after the patient's discharge from the hospital could contribute to worsen the subsequent management of diabetes [37].

Selected interventions such as a cooperative strategy between general practitioners and diabetologists or the organization of mini clinics by general practitioners or education programs can significantly improve metabolic control [38-41]. While these interventions are generically devoted to the average home-dwelling diabetic patients, present findings suggest that special attention should be paid to selected older patients discharged from the acute care hospital. These patients should benefit from a very careful supervision by the primary care providers and/or from programs aimed at optimizing the home management.

Limitations of our study deserve to be cited: 1) Fasting glycemia was the only measure of short term glycemic control. A glycemic profile would have provided a more complete and reliable estimate of the quality of therapy. However, morning hyperglycemia has been reported to be an uncommon consequence of nocturnal hypoglycemia in elderly diabetics on various therapeutic regimens [42]. Thus, it is likely that only a minority of patients classified as undertreated were exposed to an excess of hypoglycemic therapy at night. 2) Conclusions apply to older hospitalized patients and not to the general population. Thus, the proposed method aims at selecting diabetic patients amenable to special care programs after the discharge and, thus, optimizing the use of the few available economic resources. It has not been designed to target elderly homedwelling diabetics at risk of poor metabolic control; 3 ) The score was validated in a single General Medicine ward and not on multicenter basis. Thus, we cannot assume that discharge and therapeutic behaviors reflect those characterizing most of Geriatrics and General Medicine wards. This might limit the generalizability of results ; 4) Patients 
were not systematically screened for diabetic complications. This prevented us from verifying whether the presence of complications affected the therapeutic approach or had prognostic implications.

\section{Conclusions}

The present study shows that most of the older patients admitted to an acute care hospital with a primary or second-listed diagnosis of diabetes mellitus are discharged in poor metabolic control and continue to have high HbA1c levels one year after the discharge. Patients at risk of poor long term metabolic control can be effectively targeted by a simple clinical prediction rule on admission. However, attempts should be made to improve the diagnostic accuracy of the proposed clinical prediction rule by including selected presently untested variables such as the presence and severity of diabetic complications. Finally, research is needed to verify whether the identified predictors can be conveniently used to select patients amenable to dedicated home care programs.

\section{Competing interests}

None.

\section{Authors' contribution}

RAI, AC, and CP participated in the design of the study, analysis of data and drafting of the manuscript. FC carried out the collection of data regarding the testing population, and contributed to the drafing and critical revision of the manuscript. LC, and BM participated in the analysis of data and drafting of the manuscript. FP participated in the drafting and critical revision of the manuscript. PC participated in the design and coordination of the study.

\section{All authors read and approved the final manuscript.}

\section{Acknowledgements}

The Gruppo Italiano di Farmacovigilanza nell'Anziano (GIFA) is a research group of the Italian Society of Gerontology and Geriatrics (SIGG) - Fondazione Italiana per la Ricerca sull'Invecchiamento (FIRI-ONLUS).

The GIFA is partially supported by a grant from the Italian National Research Council (No 94000402).

A complete list of the GIFA investigators has been published previously (Eur J Epidemiol I5: 893-90I, 1999).

\section{References}

I. Stratton IM, Adler Al, Neil HA, Matthews DR, Manley SE, Cull CA, Hadden D, Turner RC, Holman RR: Association of glycemia with macrovascular and microvascular complications of type 2 diabetes (UKPDS 35): prospective observational study. $B M J$ 2000, $321: 405-12$

2. No Authors: Effect of intensive blood glucose control with metformin on complications in overweight patients with type 2 diabetes (UKPDS 34). Lancet 1998, 352:854-865

3. No Authors: Intensive blood glucose control with sulfonylureas or insulin compared with conventional treatment and risk of complications in patients with type 2 diabets (UKPDS 33). Lancet 1998, 352:837-853
4. Turner R, Cull C, Holman R, for the UKPDS: A 9-year update of a randomized, controlled trial on the effect of improved metabolic control on complications in NIDDM. Ann Intern Med 1996, I 24: | 36-| 45

5. Marshall CL, Bluenstein M, Briere E, Chapin C, Darling B, Davis K, Davis T, Gersten J, Harris C, Hodgin A, Larsen W, Mabb D, Rigberg $\mathrm{H}$, Watson $\mathrm{D}$, Krishnaswami V: Improving outpatient diabetes management through a collaboration of six competing, capitated Medicare managed care plans. Am J Med Qual 2000, | 5:65-7|

6. Sadur CN, Moline N, Costa M, Michalik D, Mendlowitz D, Roller S, Watson R, Swain BE, Selby JV, Javorski WC: Diabetes and management in a health maintainance organization. Efficacy of care management using cluster visits. Diabetes Care 1999, 22:20II-2017

7. Kell SH, Drass J, Bausell RB, Thomas KA, Osborn MA, Gohdes D: Measures of disease control in Medicare beneficiaries with diabetes mellitus. J Am Geriatr Soc 1999, 47:417-422

8. Meltzer S, Lieter L, Daneman D, Gerstein HC, Lau D, Ludwig S, Yale JF, Zinman B, Lillie D: 1998 clinical practice guidelines for the management of diabetes in Canada. Canadian Diabetes Association. CMAJ 1998, I59(suppl 8):SI-S29

9. Engelgau MM, Geiss LS, Manninen DL, Orians CE, Wagner EH, Friedman NM, Hurley JS, Trinkaus KM, Shatin D, Van Vorst KA: Use of services by diabetes patients in managed care organizations. Development of a diabetes surveillance system. CDC Diabetes in Managed care Work Group. Diabetes Care 1998, 21 1:20622068

10. Benjamin EM, Schneider MS, Hinchey KT: Implementing practice guidelines for diabetes care using problem-based learning. A prospective controlled trial using firm systems. Diabetes Care 1999, 22:1672-1678

II. Gerstein HC, Reddy SS, Dawson KG, Yale JF, Shannon S, Norman G: A controlled evaluation of a national continuing medical education program designed to improve family physicians' implementation of diabetes-specific clinical practice guidelines. Diabetes Med 1999, 16:964-969

12. Woolf SH, Davidson MB, Greenfield S, Bell HS, Ganiats TG, Hagen MD, Palda VA, Rizza RA, Spann SJ: Controlling blood glucose levels in patients with type 2 diabetes mellitus. An evidencebased policy statement by the American Academy of family Physicians and American Diabetes Association. J Fam Pract 2000, 49:453-460

13. Helseth LD, Susman JL, Crabtree BF, O'Connor PJ: Primary care physicians' perceptions of diabetes management. A balancing act. J Fam Pract 1999, 48:37-42

14. Larme AC, Pugh JA: Attitudes of primary care providers towards diabetes: barriers to guidelines implementation. Diabetes Care 1998, 21:1391-1396

15. Drass J, S Kell, Osborn M, Bausell B, Jr Corcoran J, Moskowitz A Fleming B: Diabetes care for Medicare beneficiaries. Attitudes and behaviors of primary care physicians. Diabetes Care 1998, 21:1282-1287

16. Lorber D: What works? The Diabetes care and information center. Diabet Med 1998, I5(suppl 4):S24-S27

17. Kell SH, Drass J, Bausell RB, Thomas KA, Osborn MA, Gohdes D: Measures of disease control in Medicare beneficiaries with diabetes mellitus. J Am Geriatr Soc 1999, 47:417-422

18. Neter J, Kutner MH, Nachtsheim CJ, Wasserman W: Applied linear regression models, 3rd edition. Boston, Irwin 1996

19. Carbonin PU, Pahor M, Bernabei R, Sgadari A: Is age an independent risk factor of adverse drug reactions in hospitalized medical patients? J Am Geriatr Soc 1991, 39:1093-1099

20. Pahor M, Guralnik JM, Gambassi G, Bernabei R, Carosella L, Carbonin $\mathrm{PU}:$ The impact of age on risk of adverse drug reactions to digoxin. J Clin Epidemiol 1993, 46: | 305-1314

21. International Classification of Disease, 9th $^{\text {thevision, Clinical }}$ Modification. Public Health Service, Health Care Finance Administration, Washington, 1980

22. Katz S, Ford AB, Moskowitz RW, Jackson BA, Jaffe MW: Studies of illness of the aged. The index of ADL: a standardized measure of byological and psychosocial function. JAMA 1963, 185:94-101

23. Hodkinson HM: Evaluation of a mental test score for assessment of mental impairment in the elderly. Age Ageing 1972, I:233-238 
24. Rocca WA, Bonaiuto S, Lippi A, Luciani P, Pistarelli T, Grandinetti A, Cavarzeran F, Amaducci L: Validation of the Hodkinson abbreviated mental test as a screening instrument for dementia in an Italian population. Neuroepidemiology 1992, I I:288-295

25. Charlson ME, Pompei P, Ales KL, MacKenzie CR: A new method of classifying prognostic comorbidity in longitudinal studies: development and validation. J Chron Dis 1987, 40:373-383

26. Worlh Health Organization: International Drug Monitoring The role of the hospital. WHO Tech Rep 1969, 452:

27. No Authors: Classification and diagnosis of diabetes mellitus and others categories of glucose intolerance. National Diabetes Data Group. Diabetes 1979, 28:1039-1057

28. Gabir MM, Hanson RL, Dabelea D, Imperatore G, Roumain J, Bennett PH, Knowler WC: The 1997 American Diabetes Association and 1999 World Health Organization criteria for hyperglycemia in the diagnosis and prediction of diabetes. Diabetes Care 2000, 23:1 108-1II2

29. Engelman L: Stepwise logistic regression. In: BMDP Statistical Software Manual (Edited by: Dixon WJ, Brown MB, Engelman L) Berkeley, University of California Press 1988, 941-970

30. Hanley JA, McNeil BJ: The meaning and use of the area under a receiver-operating characteristics (ROC) curve. Radiology 1982, I 43:29-36

31. Munoz E, Chalfin D, Birnbaum E, Goldstein J, Cohen J, Wise L: Hospital costs, use of resources, and dynamics of death associated with diabetes mellitus. South Med J 1998, 82:300-304

32. Wagner EH, Sandhu N, Newton KM, McCulloch D, Ramsey SD, Grothaus LC: Effect of improved glycemic control on health care costs and utilization. JAMA 200I, 285: I82-189

33. Meneilly GS, Cheung E, Tuokko H: Counterregolatory response to hypoglycemia in the elderly patient with diabetes. Diabetes 1994, 43:403-410

34. The Large State Peer Review Organization Consortium: Heart Failure Treatment with angiotensin-converting enzyme inhibitors in hospitalised patients in 10 large studies. Arch Intern Med 1997, 1 57:1103-I 108

35. Bart BA, Gattis WA, Diem SJ, O'Connor CM: Reasons for underuse of angiotensin-converting enzyme inhibitors in patients with heart failure and left ventricular dysfunction. Am J Cardiol 1997, 79: III8-II20

36. Larme AC, Pugh JA: Attitudes of primary care providers towards diabetes: barriers to guidelines implementation. Diabetes Care 1998, 21:1391-1396

37. Liesenfeld B, Heekern H, Schade G, Hepp KD: Quality of documentation in medical reports of diabetic patients. Int J Qual Health Care 1996, 8:537-542

38. Varroud-Vial M, Mechaly P, Joannidis S, Chapiro O, Pichard S, Lebigot A, Moulunguet M, C Attali, Bayle A, Benier J, Charpentier G: Cooperation between general practitioners and diabetologists and clinical audit improve the management of type 2 diabetic patients. Diabetes Metab 1999, 25:55-63

39. Singh BM, Holland MR, Thorn PA: Metabolic control of diabetes in general practice clinics: comparison with a hospital clinic. BMJ 1984, 289:726-728

40. Sadur CN, Moline N, Costa M, Michalik D, Mendlowitz D, Roller S, Watson R, Swain BE, Selby JV, Javorski WC: Diabetes management in a health maintenance organization. Efficacy of care management using cluster visits. Diabetes Care 1999, 22:201 I2017

4I. Benjamin EM, Schneider MS, Hinchey KT: Implementing practice guidelines for diabetes care using problem-based learning. A prospective controlled trial using firm systems. Diabetes Care 1999, 22:1672-1678

42. Havlin CE, Cryer PE: Nocturnal hypoglycemia does not commonly result in major morning hyperglycemia in patients with diabetes mellitus. Diabetes Care 1987, 10:141-147

\section{Pre-publication history}

The pre-publication history for this paper can be accessed here:

http://www.biomedcentral.com/1471-2318/2/4/prepub

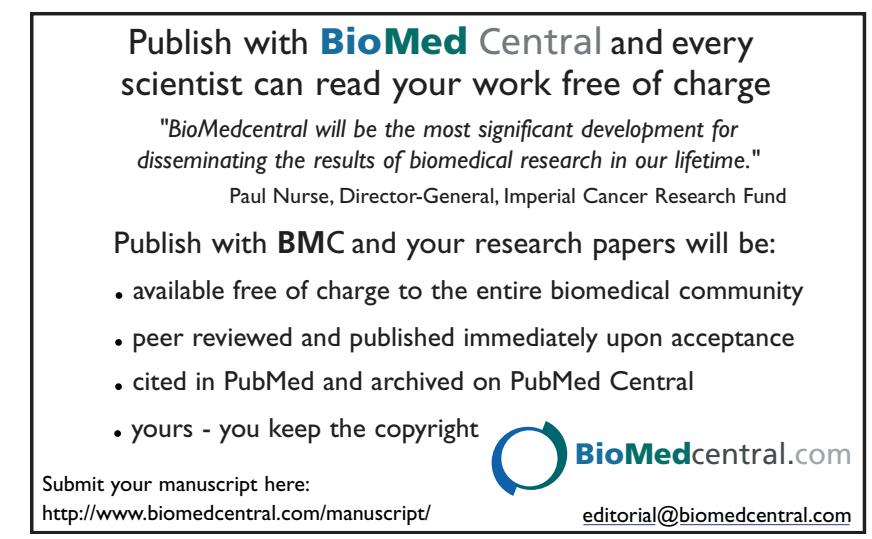

